\title{
A Review of Recent Research on Carbon Neutrality in Forest Bioenergy Feedstocks
}

\author{
Heesung Woo* and Paul Turner \\ ARC Centre for Forest Value, University of Tasmania, Australia
}

Submission: May 10, 2019; Published: May 23, 2019

*Corresponding author: Heesung Woo, ARC Centre for Forest Value, Discipline of ICT, College of Science and Engineering, University of Tasmania, Hobart TAS 7001, Australia

Abstract

Increased fuel costs and environmental concerns have contributed to renewable energy sources rising in relevance as alternatives to fossil fuels. One important part of available renewable energy is forestry biomass resources that in many countries are already classified, counted and used as renewable materials and sources of bioenergy. This review paper reflects on recent research published over the last ten years into forestry bioenergy resources and highlights marked differences in the impact and contribution to climate change made by different types of forest bioenergy feedstocks. The two main types of forest bioenergy feedstocks discussed are

(i)Forest biomass residues and

(ii) Forests grown specifically as energy trees.

Importantly the paper highlights that while both sources are discussed as viable sources of carbon-neutral renewable energy, emerging evidence confirms that it is only forest biomass residues that may reasonably be included in debates on the carbon neutrality of biomass energy feedstocks. Explicitly distinguishing between the differential contributions that forestry bioenergy feedstocks are making to climate change through carbon emissions should lead to the more appropriate policy and practice settings around forest bioenergy feedstock utilisation into the future. It is also anticipated that this paper will contribute to reducing confusion in what are increasingly polarised debates on 'good' or 'bad' sources of biomass for bioenergy.

Keywords: Forest biomass; Energy wood tree; Forest residue; Terminology; Carbon neutrality

\section{Introduction}

Increased fossil fuel costs and environmental concerns have contributed to renewed interest and investment in biomass sources for energy production and bio-based products. One major identified source of renewable biomass for bioenergy is from forests. Woody biomass is increasingly being identified and processed as a valuable resource for bio-energy with new energy production technologies and techniques being continuously advanced. The European Union (EU) has announced that 20\% of energy will be generated from renewable sources including bioenergy by 2020 [1]. Across the member States of the European Union biomass contributed $8.2 \%$ of total final energy consumption in 2010 , at the time, this already constituted $64 \%$ of European renewable energy [2]. Forest biomass remains the dominant feedstock contributing over $50 \%$ of total biomass for bio-energy production [3].

In the United States, biomass is also a key contribution to energy production. The total energy from biomass supplied approximately 2.9 quadrillion Btu of energy in 2003 [4]. The current main biomass resources consist of a wide range of forestry and agricultural resources such as industrial processing residues, and municipal solid and urban wood residues.

Significantly, however, these estimates of the total contribution of biomass to bioenergy exhibit some issues relating to the diversity and ambiguity of definitions being used to calculate available biomass resources and where they are located along bioenergy supply chains. These definitional challenges are particularly problematic about forests as sources of biomass for bioenergy. According to previous research in forest biomass utilisation, it has been revealed that forests contributions to carbon emissions in bioenergy production vary considerably depending on the source of the woody biomass used. Two key distinctions on the sources of forestry biomass are

(i) Forestry residues, or

(ii) Grown energy trees. 
Although there is a significantly different impact on climate change related emissions between using logging residues as opposed to energy forest trees, there has been a tendency in many estimation methods to 'lump them together' under renewable forest biomass for bioenergy. This has in-turn, contributed to policies and practices in some jurisdictions that are encouraging forestry biomass for bioenergy production that is questionable in terms of their environmental credentials [5].

Undoubtedly issues associated with the lack of precision in forest biomass definitions and terminologies has contributed to the emergence of controversy around forests as sources of renewable energy policy in many countries. In this context, this paper reviews research on forests as viable sources of bioenergy through the lens of their potential impact on climate change from their carbon emissions. The paper highlights the marked differences in carbon emissions between the use of logging residues and dedicated forests of energy trees as feedstocks for bioenergy production and consumption along forestry supply chains. Importantly the paper highlights that while both sources are discussed as viable sources of carbon-neutral renewable energy, emerging evidence confirms that it is only forest biomass residues that may reasonably be included in debates on the carbon neutrality of biomass energy feedstocks.

This review was prepared as part of research being undertaken within the ARC Centre for Forest Value into a prefeasibility study for enhancing Tasmania's emerging forestry biomass industry. It is however anticipated that it will also be useful for other organisations and researchers working in this or related fields in Australia and Internationally. This review aims to contribute to help inform future work in the area of forest biomass and woody biomass utilisation and bio-based industry. It is also anticipated that this paper will contribute to reducing confusion in what are increasingly polarised debates on 'good' or 'bad' sources of biomass for bioenergy.

\section{Climate Change and Forest Biomass Energy Utilisation}

Previous research has presented evidence that forest residues and woody waste utilisation as biomass energy feedstock could compensate for carbon release [6-8]. The argument presented being that forest residues and woody wastes materials quickly decompose and release their carbon in forests over time anyway and that advances in bioenergy generation may compensate for and reduce overall carbon release [9]. In other essence, the argument being that using forest residues may be considered carbon neutral in their use as biomass energy feedstocks $[8,9]$.

By contract, sourcing of biomass feedstocks from dedicated forests of energy trees planted and grown specifically as bioenergy feedstock contributes to increasing carbon emissions into the atmosphere $[7,8,10,11]$. Indeed, according to research conducted by Mckechnie et al. [5], increasing the scale of forest energy trees production and harvesting as feedstock for bioenergy can be expected to emit even more carbon into the atmosphere than using fossil fuels over the short-term $[5,6,11]$. Perhaps unsurprisingly these differences in the impact of forestry biomass feedstocks on carbon emissions have generated controversy in the wider community. Unfortunately, however, the lack of precision in much debate on forest biomass feedstocks has clouded discussions and led to some confusing policy settings around forest biomass for bioenergy. Many communities and Non-governmental Organizations (NGO) are now actively campaigning against forestry biomass feedstocks for bioenergy under the banner of 'big bad bio-energy' < http:// bigbadbioenergy.com/> aiming to prohibit the growing or use of dedicated energy trees for use as bioenergy feedstocks and to limit the use of biomass to forest residues and/or highly efficient biomass co-generation energy plants [12].

The reality of the carbon emission risks posed from energy trees has polarised debates about woody biomass and prevented a more balanced and evidence-based discussion about the merits of forest residues as sources of bioenergy feedstocks. This paper argues for forest biomass utilisation debates to be based on strong scientific evidence and for recognition of the potential of forest residues to meaningfully contribute as part of a suite of renewable biomass feedstocks under well-defined and monitored circumstances.

Internationally, many examples of biomass utilisation exist, and these have frequently been used to demonstrate the potential of these energy sources within renewable energy debates. Unfortunately, however, when many of these examples are examined more scientifically, it emerges that only a very limited number are projects that from a carbon emissions perspective genuinely contribute to debates on climate action balanced alongside socio-economic benefits from locally sourced biomass feedstocks, especially for regional socio-economic development.

Europe is often heralded as an exemplar of forestry biomass for bioenergy utilisation. The total harvested wood volume in Europe is almost the same as the amount of timber production in the whole of North America (the US and Canada combined). Searchinger et al. [7] point out that if forest biomass energy consumption continues to increase to $40 \%+$ of 2015 harvest levels, the required additional woody biomass feedstock would equal all of Europe's wood harvest [7].

Most significantly, the recent renewable energy directive (RED) has introduced a new biomass energy plan to increase by $10 \%$ renewable sources of heat energy generation by 2020 . For heating energy, most of the applicable energy sources are from woody biomass energy feedstocks. To meet the demand of the new plan, the predicted woody biomass amount is approximately $50 \%$ of Europe's current annual wood harvest $[13,14]$. Unfortunately, a potentially detrimental impact of this policy to support biomass energy utilisation may be to expand energy tree harvesting rates in forests all over the world and inadvertently contribute negatively to deforestation, climate change and biodiversity. 
The critical challenge here being whether the forestry feedstocks being utilised in bio-energy are by-products of other commercial forestry practices such as logs for timber construction, veneers or engineered wood products or whether they are primarily grown and harvested as dedicated energy tree forests. As discussed above, current evidence suggests that energy trees supply chains will contribute to increased carbon emissions rather than have a neutral impact or even reduce emissions as may be the case when genuine forest residues are utilised in bioenergy production especially when locally sourced.

Forest residues as by-products from conventional timber harvesting can be defined as small-diameter trees, tops, limbs, and wood chunks that do provide an opportunity to produce bioenergy and bio-based forest products in a more carbon neutral manner [15]. Some countries are using harvesting and hauling forest residues to become successful feedstocks in bioenergy production as a genuine alternative to fossil fuels and to contribute positively to reducing overall carbon emissions. New technologies and techniques in combustion, gasification, palletisation, pyrolysis, briquettes, and torrefaction are increasingly able to convert forest residues into high quality and sustainable feedstocks for bioenergy and bio-based materials $[16,17]$ in certain forestry bioenergy supply chains. With care, underutilised forest residues can be successfully harvested and converted into bioenergy feedstocks, although it is very important that any analysis includes the entire supply chain including haulage and energy feedstock production. That stated evidence suggests that forest residues can with appropriate forestry management practices also positively contribute to forest fire hazard risk reduction.

\section{Conclusion}

This short review paper has highlighted some of the evidence on the differential impacts on climate change from carbon emissions generated through forestry biomass feedstocks for bioenergy. Importantly the paper highlights a major distinction between utilisation of forestry residues and the use of dedicated energy trees from the perspective of carbon emissions and climate change impacts.

Significantly, while promoting a stronger evidence-based debate on the use of forest residue as biomass feedstock the paper has also highlighted that this assessment must consider the entire production and consumption supply chain to be able to meaningfully evaluate the overall impact on carbon emissions from this renewable energy feedstock. From this carbon emissions perspective, forest harvesting residue and forest processing residue materials should be the primary source of biomass energy feedstock and not dedicated energy trees. The authors are not suggesting that all uses of biomass residues for bioenergy production are carbon neutral, but rather, the impact can only be meaningfully determined when analyses of the entire biomass residues supply chain are conducted. There are however circumstances where it is possible to harvest, haul, process and use forest residues as feedstocks in carbonneutral bioenergy production, especially where the feedstocks are sourced locally and are not transported too far by truck for processing. Furthermore, when residues are used for bioenergy in this way, they may be especially useful in regional economies for positively balancing socio-economic and environmental values. To facilitate these discussions, it is imperative that more precise and accurate biomass residue estimation techniques are developed as well as enhanced modelling of biomass supply chain costs and estimations of the socio-economic impact of these types of bioenergy supply chains.

\section{Acknowledgement}

The authors wish to acknowledge the support of the Australian Research Council (ARC) research project called: The ARC Centre for Forest Value <www.utas.edu.au/arc-forestvalue>.

\section{References}

1. Union I (2014) Communication from the Commission to the European Parliament, the Council, the European Economic and Social Committee and the Committee of the Regions, Brussels.

2. (2012) Association, A.E.B., European Bioenergy Outlook 2012. Brussels.

3. Mantau U, et al. (2010) Real potential for changes in growth and use of EU forests. EUwood. Final report.

4. Perlack RD, Wright LL, Turhollow AF, Graham RL, Stokes BJ, et al. (2005) Biomass as feedstock for a bioenergy and bioproducts industry: the technical feasibility of a billion-ton annual supply. Oak Ridge National Laboratory, USA.

5. McKechnie J, Colombo S, Chen J, Mabee W, MacLean HL (2010) Forest bioenergy or forest carbon? Assessing trade-offs in greenhouse gas mitigation with wood-based fuels. Environ Sci Technol 45(2): 789-795.

6. Zanchi, G, Pena N, Bird N (2012) Is woody bioenergy carbon neutral? A comparative assessment of emissions from consumption of woody bioenergy and fossil fuel. Gcb Bioenergy 4(6): 761-772.

7. Searchinger TD, Beringer T, Holtsmark B, Kammen DM, Lambin EF, et al. (2018) Europe's renewable energy directive poised to harm global forests. Nat Commun 9(1): 3741.

8. Laganière J, Pare D, Thiffault E, Bernier PY (2017) Range and uncertainties in estimating delays in greenhouse gas mitigation potential of forest bioenergy sourced from Canadian forests. Gcb Bioenergy 9(2): 358-369.

9. Agency IE (2017) Tracking Clean Energy Progress: 2017. International Energy Agency Paris, France.

10. Mitchell SR, Harmon ME, O'connell KE (2012) Carbon debt and carbon sequestration parity in forest bioenergy production. Gcb Bioenergy 4(6): 818-827.

11. Holtsmark B (2013) The outcome is in the assumptions: analyzing the effects on atmospheric CO 2 levels of increased use of bioenergy from forest biomass. Gcb Bioenergy 5(4): 467-473.

12. (2019) Bioenergy, B.b, International day of action on bioenergy.

13. Hennenberg K, et al. (2017) Short analysis of the RED 2009, the iLUC Directive 2015 and the 2016 RED proposal regarding implications for nature protection. Oeko-Institute and IFEU, Berlin, Darmstadt, Heidelberg. 
14. (2017) Agency E E, Renewable energy in Europe - 2017 Update. Recent growth and knock-on effects. (European Environment Agency, Copenhagen)

15. Woo H, Acuna M, Moroni M, Taskhiri MS, Turner P (2018) Optimizing the location of biomass energy facilities by integrating Multi-Criteria Analysis (MCA) and Geographical Information Systems (GIS). Forests 9(10): 585.
16. Han HS, Jacobson A, et al. (2018) Waste to Wisdom: Utilizing forest residues for the production of bioenergy and biobased products. Applied Engineering in Agriculture 34(1): 5-10.

17. Woo H, Han HS (2018) Performance of screening biomass feedstocks using star and deck screen machines. American Society of Agricultural and Biological Engineers 34(1): 35-42.

\section{Your next submission with Juniper Publishers} will reach you the below assets

- Quality Editorial service

- Swift Peer Review

- Reprints availability

- E-prints Service

- Manuscript Podcast for convenient understanding

- Global attainment for your research

- Manuscript accessibility in different formats (Pdf, E-pub, Full Text, Audio)

- Unceasing customer service

Track the below URL for one-step submission https://juniperpublishers.com/online-submission.php 